\title{
Ambivalence and Self-Reported Adherence to Recommendations to Reduce the Spread of COVID-19
}

\author{
Iris K. Schneider@, Angela R. Dorrough, and Celine Frank \\ Department of Psychology, University of Cologne, Germany
}

\begin{abstract}
Governments worldwide still, to some extent, rely on behavioral recommendations to reduce the spread of COVID-19. We examine the role of ambivalence toward both the specific recommendations (micro-ambivalence) and the pandemic as a whole (macro-ambivalence) about compliance. We predict that micro ambivalence relates negatively, whereas macro ambivalence relates positively to self-reported adherence to recommendations. We present two studies $(N=691)$ supporting our hypotheses: the more ambivalent people are toward the behavioral recommendations (micro-level), the less they report following them. Conversely, the more ambivalent people are about the pandemic as a whole (macro-level), the more they report following recommendations. Our findings were replicated in a US sample and a representative German sample.
\end{abstract}

Keywords: COVID-19, ambivalence, behavioral change, attitudes, mixed feelings

Since the global outbreak of COVID-19 in early 2020, more than 200 million people worldwide have been infected with this novel coronavirus, and more than 4 million people have died (Status: August 10th, 2021; World Health Organization, 2021a). Since December 2020, many countries have begun to vaccinating their populations (Carvalho et al., 2021). However, vaccination progress is slow (Hunter, 2021; World Health Organization, 2021b). Therefore, many governments still rely on non-pharmaceutical interventions, such as wearing facemasks, social distancing measures, and closure of public places, to contain the threat of COVID-19 (Bundesministerium für Gesundheit, 2021). Indeed, since the spring of 2020, many governments have implemented at least some such measures some of the time. The success of such measures is entirely dependent on the degree to which people adhere to them. In the current paper, we examine how ambivalence - positive and negative thoughts and feelings at the same time - is related to self-reported adherence.

We build on research examining the relationship between ambivalence and behavior in response to environmental problems. As is the case with global pandemic, environmental problems require individuals to change their behavior - for example, engage in recycling behaviors - to reduce the negative effects of a higher-level problem. Research in this area has demonstrated an association between people's ambivalence and the degree to which they reported engaging in recycling behaviors. However, the direction of this association - that is, whether ambivalence helps or hinders - is dependent on the level of ambivalence. Specifically, ambivalence toward the actual behavior recycling (i.e., micro ambivalence) is negatively related to engaging in that behavior. In contrast, ambivalence toward environmental problems as a whole (i.e., macro ambivalence), which stems from a combination of hope (positive) and worry (negative), is positively related to engaging in recycling behavior.

In this paper, we apply this distinction between different levels of ambivalence to the COVID-19 pandemic and focus on (a) ambivalence toward the behaviors aimed at preventing the spread of COVID-19 (micro ambivalence), and (b) ambivalence stemming from hope and worry associated with the pandemic (macro ambivalence). We predict that micro ambivalence will be negatively related to selfreported adherence to the measures, whereas macro ambivalence will be positively associated with self-reported adherence (in line with Ojala, 2008). As such, our work applies ambivalence research from environmental problems and recycling to the COVID-19 pandemic.

The current paper also makes a theoretical contribution. First, we examine the relationship of the two levels of ambivalence about a single behavior. Specifically, we predict that micro objective ambivalence will negatively affect self-reported adherence, whereas macro objective ambivalence will have a positive effect on self-reported adherence. This allows us to examine their unique, relative effect and 
compare different sources of ambivalence directly. Second, if our hypothesis about macro ambivalence is confirmed, we also add to a growing body of research demonstrating that ambivalence from emotions can have beneficial effects on behavior (Berrios et al., 2018; Hershfield et al., 2013; Plambeck \& Weber, 2009; Rees et al., 2013; Rothman et al., 2017; Rothman \& Melwani, 2017). Specifically, we expand research in this domain by examining ambivalence from two very specific emotions, namely hope and worry. Finally, our study may advance our understanding of how complex reactions to micro versus macro aspects of an issue increase the precision with which behavioral change and compliance may be predicted. In the following, we briefly introduce the concept of ambivalence and delineate our rationale for each prediction. We then present two studies examining our hypotheses.

\section{Ambivalence}

In the broadest sense, ambivalence refers to the presence of positive and negative thoughts and feelings toward an object of thought (Cacioppo \& Berntson, 1994; Schneider \& Schwarz, 2017; van Harreveld et al. 2009). It occurs when people encounter an object, issue, person, or situation that simultaneously elicits positive and negative evaluations. People may be ambivalent about a wide range of topics. For instance, ambivalence has been documented for interpersonal relationships, such as with the romantic partner (Righetti et al., 2020), parents (Lüscher \& Pillemer, 1998; Maio et al., 2000) or marriage (Signorielli, 1991), health and food choices (Gillebaart et al., 2016; Povey et al., 2001; Schneider et al., 2019; Sparks et al., 2004), and societal issues, such as abortion and organ donation (Alvarez \& Brehm, 1995; Nohlen 2015; Schneider et al., 2015).

Research on ambivalence distinguishes between two main aspects of ambivalence. First, objective ambivalence is the degree to which positive and negative evaluations toward an object, topic, or situation are in accordance with each other. Objective ambivalence increases with the strength and similarity of the positive and negative evaluations. That is, objective ambivalence is highest when both positivity and negativity are strong and similar in strength. Subjective (or experienced) ambivalence refers to people's metacognitive awareness of their ambivalence. This aspect is important because people can hold positive and negative evaluations simultaneously without experiencing strong feelings of conflict. Subjective ambivalence is thus a window into people's awareness and experience of the degree of conflict and contradiction in their evaluations.

Objective ambivalence is a prerequisite for subjective ambivalence (for exceptions, see Gebauer et al., 2013). In order to experience ambivalence, people need to hold both positive and negative evaluations about the same object of thought. As a result, objective and subjective ambivalence have a positive relationship. The higher the people's objective ambivalence, the higher their subjective ambivalence. However, the magnitude of the relation between objective and subjective ambivalence varies markedly, in some studies even ranging from $r=.16$ to $r=.60$ (Snyder \& Tormala, 2017). One possible explanation is that the degree of subjective ambivalence people experience given the same level of objective ambivalence varies between individuals. For some people, the relationship between objective and subjective ambivalence is strong, whereas it is rather weak for others. This means that - given the same level of objective ambivalence - one individual can experience high levels of subjective ambivalence, while another experiences only low levels (Simons et al., 2018). Situational factors also play a role. For instance, subjective ambivalence increases with perceived attitude discrepancy with other people (Priester \& Petty, 2001), is influenced more strongly by negativity than positivity (Snyder \& Tormala, 2017), and increases when people are forced to make a dichotomous choice (Van Harreveld et al., 2009).

Taking the above into account, we build our hypothesis on objective ambivalence for two reasons. First, we directly draw on work about recycling that also examines objective ambivalence (Ojala, 2008). Second, objective ambivalence is a prerequisite for subjective ambivalence and is less sensitive to context. However, because readers might be interested in the effects of subjective ambivalence, we also include this measure in our research but refrain from making a priori predictions.

\section{Micro Ambivalence and Adherence}

Recommendations to reduce the spread of COVID-19 have been aimed at different domains, such as social gatherings, hygiene, and behavior in public spaces. One commonality is that, for most people, the recommendations constitute a departure from their typical behavior and thus require the adoption of unaccustomed behavior. The positive effects of following the recommendations can hardly be overstated: the reduced spread of disease and fewer deaths. Despite this clear incentive, many recommendations are also associated with immediate negative consequences. For instance, recommendations to reduce social traffic by urging people to stay home, limiting group size, and closing spaces where people gather cause an immediate reduction in social contact, intimacy, and connectedness. More generally, most behavioral recommendations require effort and involve restriction. As such, although there are clear positive effects of adhering to recommendations, individuals also face downsides, making ambivalence likely.

There are at least three reasons for assuming that ambivalence will negatively relate to adherence. First, when 
people are ambivalent about a certain issue, their reactions to that issue become inconsistent (Conner \& Armitage, 2008). Thus, the more ambivalent people are about the measures, the less consistent they follow the recommended behaviors. Thus, greater ambivalence leads to less adherence overall because individuals do not adhere to all recommendations all the time. Second, unlike strong positive or negative attitudes, ambivalent attitudes about a behavior do not provide clear guidance in the moment of decisionmaking (Armitage \& Conner, 2000; van Harreveld et al., 2015) and often leads to delayed decision-making (Bargh et al., 1992; Bassili, 1996; Gillebaart et al., 2016; Nohlen, 2015; Schneider et al., 2015; Schneider \& Mattes, 2021; van Harreveld et al., 2004, 2015). Thus, the more ambivalent people are about the recommendations, the more difficult it becomes to decide what to do, leading to inaction and less adherence. Finally, when people are presented with an issue or object that has been described with both positive and negative features and are forced to choose about it, they tend to choose the negative or rejecting response (Nohlen et al., 2019). Thus, when people are faced with whether to adhere to recommendations about which they feel ambivalent, they may be less likely to adhere.

Support for the idea that ambivalence toward behaviors is negatively associated with performing those behaviors stems from research on environmental problems. Researchers examined the association between ambivalence and recycling behavior and found that ambivalence toward recycling - micro ambivalence - was associated with less self-reported recycling (Ojala, 2008) and pro-environmental behavior (Costarelli \& Colloca, 2004). We predict a similar pattern for ambivalence toward recommendations to prevent the spread of COVID-19. Specifically, we hypothesize that:

Hypothesis 1 (H1): Micro objective ambivalence is negatively related to self-reported adherence to measures to prevent the spread of COVID-19. ${ }^{1}$

\section{Macro Ambivalence and Adherence}

Most research on the relationship between ambivalence and behavioral change has focused on ambivalence about the behavior itself, that is, micro ambivalence. However, as Ojala (2008) demonstrated, macro ambivalence - positive and negative feelings about the larger problem that necessitates the behavior in the first place - also plays a role with regard to the degree to which people engage in those behaviors. To our knowledge, Ojala (2008) was the first to make the distinction between micro and macro ambivalence in relation to the same behavior. However, there is reason to believe that examining the effect of macro ambivalence may be fruitful for understanding behavioral compliance in the COVID-19 pandemic.

During the COVID-19 pandemic, many people experienced increased worry and stress (Adamson et al., 2020; Gamonal-Limcaoco et al., 2021). Such negative feelings can signal a need for change and facilitate change in existing habits (Marcus, 2010; Marcus et al., 2000). However, positive evaluations can help people deal with the consequences of such negative emotions and support coping and action. For instance, when distress co-occurs with positive affect, people are more successful in coping with the negative event and taking action that benefits their psychological well-being (Folkman \& Moskowitz, 2000). Such simultaneous activation of positive and negative emotions can reduce stress (Larsen et al., 2003). As a practical demonstration, young people worried about environmental problems are better able to bear those worries when they also experience hope and meaning (Ojala, 2005).

Thus, we assume that macro ambivalence might enable people to take action in the face of negative events and should therefore be positively associated with behavior change and intention. This expectation is in line with previous work on environmental problems. People who experience high degrees of hope combined with high degrees of worry in relation to environmental problems were more likely to engage in recycling behavior (Ojala, 2008). As such, it is plausible that ambivalence arising from positive and negative feelings about the pandemic will also have a positive relationship with adherence to recommendations to reduce the spread of COVID-19. Thus, we include a second, more novel hypothesis in our current work:

Hypothesis 2 (H2): Macro objective ambivalence is positively related to self-reported adherence to measures to prevent the spread of COVID-19. ${ }^{2}$

\section{Current Studies}

To examine these hypotheses, we conducted three studies. We report two studies in the main text and one additional study in the Electronic Supplemental Material, ESM 1. In each study, we examine how ambivalence toward the recommendations - the micro-level - is related to self-reported adherence. Second, we examine the relationship between ambivalence resulting from positive and negative feelings about the pandemic - the macro-level - and self-reported adherence. As stated above, we focus mainly on objective ambivalence because it reflects the degree of conflict

\footnotetext{
${ }^{1}$ Note that the hypotheses are listed in a different order in our preregistrations.

${ }^{2}$ Note that the hypotheses are listed in a different order in our preregistrations.
} 
between separate evaluations held by an individual (Thompson et al., 1995; van Harreveld et al., 2015). However, for exploratory purposes, in all studies, we also examine subjective ambivalence. Subjective ambivalence refers to the subjective feeling of conflict that an individual experiences in response to a given topic or issue (Priester \& Petty, 1996; Schneider \& Schwarz, 2017). We describe these measures in more detail in the Method sections.

We report how we determined our sample size, all data exclusions (if any), and all measures in the studies. We preregistered all studies and conducted analyses in line with the preregistration using statistical analyses packages in $\mathrm{R}$ (R Core Team, 2020). For confirmatory analyses, we report one-sided $p$-values for directional hypotheses. In each study, we also included multiple additional variables for exploratory purposes. Analyses relevant to the research here are reported in the Results sections - additional analyses can be found in the supplemental material. Data, materials (including all measures), and analysis scripts can be found on the Open Science Framework page (https://osf.io/eu6k5/).

\section{Study 1: Representative German Panel}

The data for Study 1 stems from a joint study conducted by different researchers at the (Social Cognition Center Cologne). This battery already included a measure of selfreported adherence to different recommendations by the German government (Dohle et al., 2020) for a different purpose. To test our hypothesis that micro objective ambivalence about the recommendations is negatively related to self-reported adherence to recommendations to prevent the spread of COVID-19 and that macro objective ambivalence about the pandemic is positively related to self-reported adherence, we added measures of ambivalence to the study battery, allowing us to test our predictions in a representative sample (with regard to age and gender) of the German population. The study was preregistered here: https://aspredicted.org/blind.php? $\mathrm{x}=\mathrm{zy} 34 \mathrm{vj}$.

\section{Method}

Three hundred one participants $\left(M_{\mathrm{age}}=50.06, S D=16.15\right.$; 156 women, 143 men, 1 diverse) were recruited through the online panel provider Toluna (https://de.toluna.com/\#/). Income, occupation, and education were broadly distributed in the sample. Data were collected as part of the COVID-19 battery (collected at the Social Cognition Center Cologne). The battery included three other studies
(Glöckner et al., 2020; Hellmann et al., 2021; Imhoff \& Lamberty, 2021) that altogether took participants $25 \mathrm{~min}$ to complete. Data collection took place between April 29th, 2020 and May 4th, 2020. At that time, the German population had lived under substantial restrictions of work and daily life (e.g., closing of non-essential institutions and businesses, contact restrictions, working from home) for 6 weeks. The sample size was set by the overarching project at $N=300$ to detect small effects for regression coefficients (assumed $f^{2}=.036$, one-sided test) with a power of $1-\beta=.95$. A sensitivity analysis shows that a sample size of 300 and an $\alpha$-level of .05 would ensure $84 \%$ Power to detect an H1 slope of .15 and $99 \%$ power to detect an $\mathrm{H} 1$ slope of .30 .

\section{Materials and Procedure}

\section{Ambivalence}

As stated above, in ambivalence research, there is a distinction between objective and subjective ambivalence. Objective ambivalence gauges the degree of ambivalence in the evaluations associated with the attitude object. This is done by assessing the positive and negative evaluations with separate unipolar scales (Kaplan, 1972; Priester \& Petty, 1996; Schneider \& Schwarz, 2017; Thompson et al., 1995; van Harreveld et al., 2015). Thus, instead of placing positive and negative on opposing ends of one scale, these scales measure only the degree of positivity and negativity. To obtain an index of ambivalence, these evaluations feed into a score that takes into account both the strength of the evaluations (to distinguish from neutrality) as well as their similarity (to distinguish from univalence) (Kaplan, 1972; Schneider \& Mattes, 2021; Schneider \& Schwarz, 2017; Thompson et al., 1995).

Subjective or experienced ambivalence measures the degree of ambivalence people experience at the current moment. It is measured using a self-report scale that asks participants to indicate the degree to which they experience ambivalence. Exact items differ between studies, with some referring only to the experience of ambivalence (Schneider \& Mattes, 2021), whereas others also include items regarding affective and behavioral consequences such as indecision (Priester \& Petty, 1996) and feeling torn (Jamieson, 1993). In line with the work by Ojala (2008), we focus primarily on objective ambivalence. However, for exploratory purposes, we also included a measure of subjective ambivalence (see Exploratory Measures).

\section{Micro Objective Ambivalence About the \\ Recommendations}

Objective ambivalence about the recommendations was calculated by entering ratings of how positive and negative $(1=$ not at all to $10=$ very $m u c h)$ participants felt toward the 
recommendations to reduce the spread of COVID-19 into the following formula:

$$
((\mathrm{P}+\mathrm{N}) / 2)-\operatorname{abs}(\mathrm{P}-\mathrm{N}) .
$$

This measure quantifies the degree to which positivity and negativity are both strong and similar (Thompson et al., 1995). The stronger and more similar the ratings are, the more ambivalent participants are and the higher their score on this index. This index ranges between -3.5 (= maximal univalence) and 10 (= maximal ambivalence).

\section{Macro Objective Ambivalence About the Pandemic}

In line with Ojala (2008), we measured objective ambivalence about the pandemic by asking participants how hopeful and worried $(1=$ not at all to $10=$ very much $)$ they felt when they thought about the COVID-19 pandemic (note that worry was assessed with the German word "besorgt," which relates to concern and not ruminative states. For a full item list in German, see ESM 1). These ratings were entered in the same formula as above. The index again ranges between -3.5 (= maximal univalence) and 10 (= maximal ambivalence).

\section{Exploratory: Subjective Ambivalence}

In addition to objective ambivalence, it is common in research on ambivalence to also examine the subjective, or felt, an ambivalence that people experience (Jamieson, 1993; Priester \& Petty, 1996). This measure directly assesses experienced conflict by asking participants to self-report their ambivalence. Thus, for exploratory purposes, we included a measure of subjective ambivalence about the recommendations and the pandemic. For subjective ambivalence about the recommendations, we asked participants to what degree they experienced conflicting thoughts and feelings with regard to the recommendations they should follow $(1=$ not at all to $10=$ very strong $)$. For subjective ambivalence about the pandemic, we asked participants to indicate to what degree they experienced conflicting thoughts and feelings with regard to the COVID-19 pandemic $(1=$ not at all to $10=$ very strong $)$.

\section{Adherence}

We examined self-reported adherence by averaging the self-reported frequency of adherence to 12 different recommendations to prevent the spread of COVID-19 ( $1=$ never to 5 = always; Cronbach's $\alpha=.89)$ : regular hand washing, no hugging or handshaking, cough and sneeze in elbow or tissue, keep distance in public, stay at home as often as possible, work from home if possible, avoid peak hours in supermarkets, avoid larger meetings with friends and family, avoid crowds, avoid public transport, reduce contact with old or chronically ill people, wearing a mask in public
(Dohle et al., 2020). These recommendations were endorsed by the German federal government agency for disease control (Robert-Koch-Institut, https://www.rki.de/ EN/Home/homepage_node.html) at the time of the study. Age and gender were also recorded.

Finally, we performed a number of exploratory analyses on other variables. For the sake of clarity, we include the description of these measures as well as the analyses associated with them in ESM 1.

\section{Results and Discussion}

No participants were excluded based on the preregistered criteria. Objective ambivalence about the recommendations (micro objective ambivalence, $M=3.07 ; S D=3.81$ ) as well as objective ambivalence about the pandemic (macro objective ambivalence, $M=4.10 ; S D=3.42$ ) covered the full span of the index. This indicated substantial variation in our sample regarding how ambivalent people were about the recommendations and the COVID-19 pandemic. Results regarding self-reported adherence to recommendations to prevent the spread of COVID-19 showed that participants, on average, reported adhering to the recommendations quite often $(M=4.34 ; S D=0.63$, on a 5-point scale).

\section{Confirmatory Analyses}

To test our first hypothesis that micro objective ambivalence is negatively related to self-reported adherence to recommendations to prevent the spread of COVID-19, we regressed the self-reported adherence score on micro objective ambivalence (H1). Results show that the more ambivalent people were about reducing spread, the less they reported following the recommendations endorsed by German authorities, $\beta=-.07$, but this was not statistically significant (Table 1 , Model 1 ). To test the hypothesis that macro objective ambivalence is positively related to self-reported adherence to recommendations to prevent COVID-19 (H2) spread, we conducted the same analyses but with macro-ambivalence as a predictor. As predicted, macro-ambivalence was positively associated with selfreported adherence to recommendations to reduce the spread of COVID-19, $\beta=.14$ (Table 1, Model 2).

We also ran a full model (as preregistered) regressing self-reported adherence on both macro and micro ambivalence to test whether they had unique predictive value. In this model, both effects are significant in the expected direction (Table 1, Model 3). As predicted, micro objective ambivalence was significantly related to less self-reported adherence, $\beta=-.13$, and macro objective ambivalence was significantly related to greater self-reported adherence, $\beta=.20$. 
Table 1. Study 1: Self-reported adherence score predicted by (1) objective ambivalence toward the recommendations (micro), (2) objective ambivalence toward the pandemic (macro), and (3) both

\begin{tabular}{|c|c|c|c|c|c|c|c|c|c|}
\hline \multirow[b]{3}{*}{ Predictors } & \multicolumn{9}{|c|}{ Adherence to recommendations } \\
\hline & \multicolumn{3}{|c|}{ Model 1} & \multicolumn{3}{|c|}{ Model 2} & \multicolumn{3}{|c|}{ Model 3} \\
\hline & Estimates & $\mathrm{Cl}$ & $p$ & Estimates & $\mathrm{Cl}$ & $p$ & Estimates & $\mathrm{Cl}$ & $p$ \\
\hline (Intercept) & 4.38 & 4.29 to 4.47 & $<.001$ & 4.22 & 4.11 to 4.33 & $<.001$ & 4.26 & 4.14 to 4.37 & $<.001$ \\
\hline $\begin{array}{l}\text { Objective ambivalence } \\
\text { recommendations (micro) }\end{array}$ & -0.07 & -0.19 to 0.04 & .016 & & & & -0.13 & -0.24 to -0.01 & .016 \\
\hline $\begin{array}{l}\text { Objective ambivalence } \\
\text { pandemic (macro) }\end{array}$ & & & & 0.17 & 0.05 to 0.28 & .002 & 0.20 & 0.08 to 0.32 & .001 \\
\hline Observations & & 301 & & & 301 & & & 301 & \\
\hline$R^{2} / R^{2}$ adjusted & & $0.005 / 0.002$ & & & $0.027 / 0.024$ & & & $0.042 / 0.036$ & \\
\hline
\end{tabular}

Note. Estimates are standardized.

\section{Robustness}

As a robustness check of the full model (Model 3), we regressed self-reported adherence to all recommendations separately in a multilevel model (i.e., 12 different recommendations per participant; dummy-coded), instead of combining the recommendations into a single index. The pattern of results did not change (micro objective ambivalence: $\beta=-.09, t(300)=-2.24, p=.013$; macro objective ambivalence: $\beta=.13, t(300)=3.20, p<.001)$. We ran Model 3 once more, controlling for age and gender. The effect of macro objective ambivalence was robust to controlling for these demographic factors, $\beta=.18, t(294)=$ $3.18, p<.001$, but the effect of micro objective ambivalence was non-significant in this model, $\beta=-.05, t(294)=-0.96$, $p=.170$. This latter finding might have been due to the relationship between age and micro objective ambivalence in our sample. Splitting the data by the median age revealed that micro objective ambivalence as observed had an effect on behavioral adherence for participants older than $52, \beta=$ $-.16, t(146)=-2.96, p=.004$, but not for people younger than $52, \beta=.12, t(139)=0.96, p=.168$.

In sum, in line with our predictions, we found that macro objective ambivalence was related to greater self-reported adherence, whereas micro objective ambivalence was related to less self-reported adherence (although not significantly so in the univariate model) to recommendations to prevent the spread of COVID-19. Moreover, the full model including macro and micro objective ambivalence suggests that both have unique predictive values regarding selfreported adherence to COVID-19 recommendations.

\section{Exploratory Analyses}

We also examined whether the subjective experience of ambivalence is related to self-reported adherence. First, as in previous work (Newby-Clark, et al., 2002; Snyder \& Tormala, 2017), objective and subjective ambivalence about the recommendations $(M=6.10, S D=2.39)$ were correlated, $r(299)=.33, p<.001$. The association between subjective ambivalence toward the recommendations and self- reported adherence was not significant, $\beta=-.08, t(299)=$ $-1.38, p=.169$. When entering both micro objective and micro subjective ambivalence into the model, neither was significant.

Macro objective and macro subjective ambivalence about the pandemic $(M=6.32, S D=2.31)$ were also correlated, $r(299)=.22, p<.001$. Subjective ambivalence about the pandemic was not significantly related to self-reported adherence, $\beta=.02, t(299)=0.40, p=.689$. Results did not change when entering both macro objective and macro subjective ambivalence into the model.

Study 1 showed that the more micro objective ambivalence people exhibited toward the recommendations to prevent the spread of COVID-19, the less adherence they reported. In contrast, the more macro objective ambivalence people exhibited toward the COVID-19 pandemic in general, the more adherence they reported. These findings provide the first evidence for our predictions and are in line with the findings by Ojala (2008) on environmental behavior. In our exploratory analyses, neither micro nor macro subjective ambivalence was related to self-reported adherence.

\section{Study 2: North-American Sample From Prolific}

In Study 2, we aimed to test the robustness of our findings by replicating them in a different sample and recruited a US sample using the online participant pool Prolific (https:// www.prolific.co). Participants recruited through Prolific, on average, have a medium-income and a median education level of a Bachelor's degree (Peer et al., 2017). Data were collected on September 19th, 2020, when the United States had more than 6.5 million confirmed cases of COVID-19 and more than 190,000 deaths (https://coronavirus.jhu.edu/map.html). The study was preregistered here: https://aspredicted.org/blind.php? $\mathrm{x}=\mathrm{a} 4 \mathrm{eg} 2 \mathrm{k}$. 


\section{Method}

Three hundred ninety participants $\left(M_{\text {age }}=33.80\right.$ years, $S D$ = 11.40; 186 female, 195 male, 5 other, 4 not indicated) were recruited through the online panel provider Prolific (https://www.prolific.co). In Study 1, we found an effect of $f^{2}=.04$ for objective macro-ambivalence. To detect effects of that size with a one-sided test (because of the directional hypotheses), $\alpha=.05$, and $1-\beta=.80$, we would require 156 participants (assuming a multiple regression, see Model 3). For micro objective ambivalence, we found an effect of $f^{2}=.016$. To detect effects of that size with a one-sided test, $\alpha=.05$ and $1-\beta=.80$, we required 388 participants. Thus, we set the sample size to 388 and provided two additional participants by the online panel.

\section{Materials and Procedure}

We used an English translation of the materials used in Study 1. Thus, each participant completed measures on micro and macro objective ambivalence (possible range from -3.5 to 10 ), and 12 items measuring self-reported adherence to 12 different recommendations to prevent the spread of COVID-19 $(1=$ never to $5=$ always; Cronbach's $\alpha=.89$ ). Additionally, we assessed subjective ambivalence for both the macro-level ("To what degree do you have conflicting thoughts and feelings with regard to the Corona Pandemic?") and the micro-level ("To what degree do you have conflicting thoughts and feelings with regard to the recommendations you should follow?") ( 1 = not at all to $10=$ very strongly) as an exploratory variable. We also examined perceived controversy of each of the recommendations ("Please indicate for each recommendation how controversial it is in your opinion") on a 10-point scale $(1=$ not at all controversial to $10=$ very controversial $)$ for a different project - thus, we do not report analyses pertaining to this measure here. Age and gender were also recorded. Additional exploratory analyses can be found in ESM 1.

\section{Results and Discussion}

In line with our preregistration, no participants were excluded from data analyses. Objective ambivalence about the recommendations (micro objective ambivalence, $M=$ $1.60 ; S D=3.21$ ) as well as objective ambivalence about the pandemic (objective macro ambivalence, $M=2.81$; $S D$ $=3.17$ ) covered the full span of the index, indicating substantial variation in our sample with regard to how ambivalent people were about the COVID-19 pandemic and the specific recommendations. Participants reported following the recommendations to reduce the spread of COVID-19 most of the time ( $M=4.34, S D=0.61$, on a 5 -point scale).

\section{Confirmatory Analyses}

To test our hypothesis that micro objective ambivalence was negatively related to self-reported adherence, we regressed the self-reported adherence score on micro objective ambivalence. Study 1 again found that micro objective ambivalence toward the recommendations was negatively related to self-reported adherence, $\beta=-.08$ (Table 2, Model 1). To test the hypothesis that macro objective ambivalence is positively related to self-reported adherence to recommendations to prevent the spread of COVID-19, we conducted the same analysis but with macro objective ambivalence as a predictor. As expected, self-reported adherence was positively associated with objective ambivalence about the pandemic, $\beta=.14$ (Table 2, Model 2). We also ran a full model (as preregistered), regressing selfreported adherence on micro and macro objective ambivalence to test whether they had unique predictive value. Also, both effects are in the expected direction (Table 2, Model 3). As predicted, micro objective ambivalence was significantly related to less self-reported adherence, $\beta=$ -.09 , whereas macro objective ambivalence was significantly related to more self-reported adherence, $\beta=.14$, demonstrating their unique predictive effects.

\section{Robustness}

As a robustness check of the full model, we regressed selfreported adherence to all recommendations separately in a multilevel model rather than combining the recommendations into a single index. The results remained unchanged (micro-ambivalence: $\beta=-.06, t(387)=-1.68, p=.047$; macro-ambivalence: $\beta=.10, t(387)=2.85, p=.002)$. As a further robustness check, we ran Model 3 again while additionally controlling for age and gender. The effect of micro objective ambivalence remained robust, $\beta=-.02, t(385)=$ $-1.7, p=.047$, as did the effect of macro objective ambivalence, $\beta=.03, t(385)=2.87, p=.002$.

In sum, in line with our predictions, we found that objective ambivalence about the recommendations was related to less self-reported adherence, and objective ambivalence about the pandemic to more self-reported adherence to recommendations to prevent the spread of COVID-19. The more ambivalent participants were about the recommendations they had to follow, the less they reported following them. In contrast, the more ambivalent they were about the pandemic as a whole, the more they reported following recommendations to prevent the spread of the virus. These findings are in line with the findings in the full model in Study 1.

\section{Exploratory Analyses}

We also examined whether the subjective experience of ambivalence was related to self-reported adherence. As in Study 1 , micro objective and micro subjective ambivalence $(M=4.31, S D=2.62)$ were correlated, $r(388)=.41, p<.001$. 
Table 2. Study 2: Self-reported adherence score predicted by (1) objective ambivalence toward the recommendations (micro), (2) objective ambivalence toward the pandemic (macro), and (3) both

\begin{tabular}{|c|c|c|c|c|c|c|c|c|c|}
\hline \multirow[b]{3}{*}{ Predictors } & \multicolumn{9}{|c|}{ Self-reported adherence to recommendations } \\
\hline & \multicolumn{3}{|c|}{ Model 1} & \multicolumn{3}{|c|}{ Model 2} & \multicolumn{3}{|c|}{ Model 3} \\
\hline & Estimates & $\mathrm{Cl}$ & $p$ & Estimates & $\mathrm{Cl}$ & p & Estimates & $\mathrm{Cl}$ & $p$ \\
\hline (Intercept) & 4.37 & 4.30 to 4.44 & $<.001$ & 4.27 & 4.18 to 4.35 & $<.001$ & 4.29 & 4.21 to 4.38 & $<.001$ \\
\hline $\begin{array}{l}\text { Objective ambivalence } \\
\text { recommendations (micro) }\end{array}$ & -0.08 & -0.18 to 0.01 & .047 & & & & -0.09 & -0.19 to 0.01 & .037 \\
\hline $\begin{array}{l}\text { Objective ambivalence } \\
\text { pandemic (macro) }\end{array}$ & & & & 0.14 & 0.04 to 0.24 & .003 & 0.14 & 0.04 to 0.24 & .003 \\
\hline Observations & & 390 & & & 390 & & & 390 & \\
\hline$R^{2} / R^{2}$ adjusted & & $0.007 / 0.005$ & & & $0.019 / 0.017$ & & & $0.028 / 0.023$ & \\
\hline
\end{tabular}

Note. Estimates are standardized.

We found a negative association between micro subjective ambivalence about the recommendations and self-reported adherence, $\beta=-.29, t(388)=-6.03, p<.001$. Because micro objective ambivalence about the recommendations also had a negative association with self-reported adherence (see previous section), we entered both into a single model to assess their unique predictive value. In this model, micro subjective ambivalence about the recommendations remained a significant predictor of self-reported adherence, $\beta=-.31, t(387)=-5.83, p<.001$; however, micro objective ambivalence about the recommendations did not, $b=.04$, $t(387)=0.81, p=.418$. Lastly, macro objective and subjective ambivalence about the pandemic $(M=5.52, S D=2.70)$ were also correlated, $r(388)=.34, p<.001$; yet, subjective ambivalence toward the pandemic was not significantly related to self-reported adherence, $\beta=-.05, t(388)=$ $-1.01, p=.312$. Entering macro objective ambivalence into the model did not change our findings. Macro subjective ambivalence was not a significant predictor of self-reported adherence.

\section{General Discussion}

\section{Main Findings}

Behavioral recommendations made by governments to combat large-scale societal problems rely in large part on behavioral compliance. We investigated the role of objective ambivalence in self-reported adherence to behavioral recommendations to reduce the spread of COVID-19. As suggested by the findings of Ojala (2008), we hypothesized that objective ambivalence about the recommendations would be negatively related to self-reported adherence. Our results confirm our hypothesis. The greater people's micro objective ambivalence about the recommendations, the less they reported following the recommendations. We found this relationship in a representative German sample and an online US sample (full model results, see
Table 3). Our finding of a negative relationship between micro subjective ambivalence and self-reported adherence to recommendations to prevent the spread of COVID-19 is generally in line with previous research showing that ambivalence has a negative effect on subsequent behavior (for overviews, see Van Harreveld et al., 2009, 2015; Rothman \& Melwani, 2017). However, due to the correlational nature of our research, we cannot draw conclusions regarding causality.

In addition to our findings on micro ambivalence, we also found that macro objective ambivalence about the COVID19 pandemic was positively associated with self-reported adherence to recommendations. That is, the more macro objective ambivalence people demonstrated about the pandemic, the more they reported adhering to the recommendations. Notably, the relationship between macro subjective ambivalence and self-reported adherence was not affected by entering micro objective and micro subjective ambivalence into a single model. In addition, macro objective ambivalence remained a significant predictor in both studies, even when entering micro objective and micro subjective ambivalence.

These findings add to a growing literature that more broadly shows that, in some cases, emotional ambivalence can have beneficial effects on behaviors (Rothman \& Melwani, 2017; Rothman et al., 2017). For instance, mixed feelings are positively associated with greater resistance to temptations (Berrios et al., 2018) and recycling behaviors (Ojala, 2008). Furthermore, emotional ambivalence has been associated with increased judgment accuracy (Rees et al., 2013) and more innovative solutions in organizational settings (Plambeck \& Weber, 2009). We add to this literature by examining the relationships between ambivalence from two specific emotions, hope and worry, to adherence to recommendations to prevent the spread of COVID-19.

Although our findings confirmed our hypothesized relationship between micro and macro ambivalence and selfreported adherence, two things are important to keep in mind. First, our study design does not allow us to conclude 
Table 3. Both studies show the results of including both micro and macro objective ambivalence to predict self-reported adherence

\begin{tabular}{|c|c|c|c|c|c|c|}
\hline \multirow[b]{3}{*}{ Predictors } & \multicolumn{3}{|c|}{ Study 1: German sample } & \multicolumn{3}{|c|}{ Study 2: Prolific US sample } \\
\hline & \multicolumn{3}{|c|}{$\begin{array}{l}\text { Self-reported adherence to } \\
\text { recommendations }\end{array}$} & \multicolumn{3}{|c|}{$\begin{array}{l}\text { Self-reported adherence to } \\
\text { recommendations }\end{array}$} \\
\hline & Estimates & $\mathrm{Cl}$ & $p$ & Estimates & $\mathrm{Cl}$ & p \\
\hline (Intercept) & 4.26 & 4.14 to 4.37 & $<.001$ & 4.29 & 4.21 to 4.38 & $<.001$ \\
\hline Objective ambivalence recommendations (micro) & -0.13 & -0.24 to -0.01 & .016 & -0.09 & -0.19 to 0.01 & .037 \\
\hline Objective ambivalence pandemic (macro) & 0.20 & 0.08 to 0.32 & .001 & 0.14 & 0.04 to 0.24 & .003 \\
\hline Observations & \multicolumn{3}{|c|}{301} & \multicolumn{3}{|c|}{390} \\
\hline$R^{2} / R^{2}$ adjusted & \multicolumn{3}{|c|}{$0.005 / 0.002$} & \multicolumn{3}{|c|}{$0.028 / 0.023$} \\
\hline
\end{tabular}

Note. Estimates are standardized.

causality. Based on theory, we assume that ambivalence influences adherence. However, it is also possible that adherence influences ambivalence. Future research may address this possibility with manipulations of ambivalence and longitudinal designs, where changes in ambivalence over time can be used in time-lagged analyses. In addition, we examined adherence through self-report. That is, participants indicated the frequency with which they followed recommendations. This approach has an advantage over asking for behavioral intentions, which can be vulnerable to social desirability (see Thielmann et al., 2017) and forecasting errors (see Baumeister et al., 2007 for a discussion). Indeed, the observed range for self-reported adherence covered the entire spectrum, with some people reporting low and others reporting high adherence. Nevertheless, these reports do not completely or solely reflect participants' actual behavior.

\section{Exploratory Findings, Open Questions, and Future Directions}

The results for objective ambivalence found in the confirmatory analyses are in line with our hypotheses. However, research on ambivalence often also examines subjective ambivalence. Thus, in our exploratory analyses, we also investigated the effect of subjective ambivalence on self-reported adherence. In Study 1, micro subjective ambivalence was not significantly related to self-reported adherence. In Study 2, we found a significant relationship between micro subjective ambivalence and self-reported adherence. For the macro level, there were no statistically significant relationships between subjective ambivalence that is, experienced ambivalence about the pandemic and self-reported adherence.

The fact that the relationship between micro subjective ambivalence and self-reported adherence is somewhat inconsistent suggests the existence of moderating factors. Although we are cautious not to overinterpret these exploratory analyses, one interesting possibility is that, on the micro-level, the subjective experience of micro ambivalence is related to behavior only when it is accompanied by negative affect. Previous work has theorized that, compared to objective ambivalence, subjective ambivalence is more consequential for downstream behavior due to its aversive nature (Van Harreveld et al., 2009, 2015). Because the items measuring subjective ambivalence were neutrally worded (i.e., no references to conflict, indecision, feeling torn), the current data do not address this possibility. However, future work could examine the role of negative affect in the relationship between micro subjective ambivalence and adherence to behaviors.

Another interesting direction for future research was suggested by the reviewer team during the review process of this work. Specifically, they proposed that adherence might increase with ambivalence because the unambivalent attitudes are primarily negative. Conversely, adherence might decrease with ambivalence when unambivalent attitudes are mostly negative. As such, the valence of low ambivalent attitudes would moderate the influence of ambivalence on self-reported adherence. We performed additional analyses examining these possibilities. The full analyses can be found in ESM 1. However, we provide a summary here. On average, relative valence was positive on the micro-level, whereas on the macro level, it was neutral to negative. Importantly, however, our analyses did not provide evidence for the moderating role of relative valence. However, relative valence did have a main effect on self-reported adherence in 3 out of 4 studies. Notably, increases in positive valence were related to greater self-reported adherence on the micro level but less self-reported adherence on the macro level - mimicking our confirmatory findings. This is not surprising given that the computation of relative valence was similar to the objective ambivalence measure used in our confirmatory analyses. Further examination of the interplay between the valence of low ambivalent evaluations and behavioral change offers an interesting avenue for future research.

Although our findings shed light on the distinctive ways different forms of ambivalence may be related to behavior, it also raises new questions. For instance, in our work, we followed the conceptualization of Ojala (2008), distinguishing between ambivalence toward the specific behaviors and the 
problem as a whole. Ojala (2008) refers to these two aspects as micro and macro ambivalence, respectively. However, the distinction between the two is defined not just by what the ambivalence is in reference to (behaviors or pandemic) but also in terms of their constitution. Objective ambivalence toward the recommendations was based on the positive and negative evaluations of the recommendation, akin to conceptualizations of attitudinal ambivalence. In contrast, objective ambivalence toward the pandemic was calculated from people's experience of hope and worry, more akin to emotional ambivalence (Rothman et al., 2017).

Thus, although our findings, on their own, are informative about the effect of these different types of ambivalence - that is, we show that ambivalence about the recommendations has a negative relationship and that ambivalence about the pandemic a positive relationship to self-reported adherence - the underlying processes are not yet clear. Future work may clarify this further by examining both emotional and evaluative ambivalence about the recommendations and the overarching problem (the pandemic). Such work could also shed light on broader questions in research on ambivalence concerning different aspects and antecedents of mixed thoughts and feelings. Objective ambivalence about the pandemic emerged from hope and worried specifically. Thus, one open question is whether emotional ambivalence from other positive and negative emotions might have similar effects.

More broadly, micro and macro levels of ambivalence might also be seen as manifestations of concrete vs. abstract processing of events. Different psychological theories address the consequences of representing the same event at different levels of abstraction. From this perspective, ambivalence about the pandemic is more abstract than ambivalence about concrete behaviors. Abstraction levels systematically influence choice and preferences (Fiedler, 2007). For instance, higher abstraction influences whether people focus on peripheral or central features of an object (Trope \& Liberman, 2000) and shapes their preferences (Sagristano et al., 2002). Relatedly, different levels of ambivalence might be differentially associated with analytical versus holistic processing (Nisbett \& Miyamoto, 2005). Perhaps ambivalence at the micro-level requires a more analytical mode of thought, whereas ambivalence at the macro level is related to a more holistic approach. Further examination of how different levels of ambivalence relate to different thinking styles can improve our understanding of how and when ambivalence relates to behavioral change and compliance.

\section{Conclusions}

In the current work, we investigated the relationship between ambivalence and adherence to recommendations to prevent the spread of COVID-19. We found that objective ambivalence about these recommendations negatively relates to adherence to recommendations. The more objective ambivalence people experience regarding their recommendations, the less likely they are to follow them. In contrast, objective ambivalence about the pandemic was positively related to adherence. The stronger people's macro objective ambivalence toward the pandemic, the more they follow the behavioral recommendations to reduce the spread of COVID-19. Our findings show that large-scale behavioral compliance challenges are accompanied by ambivalence and that objective ambivalence about specific behaviors is related to less adherence. Moreover, we also show that objective ambivalence about the problem as a whole can increase adherence. Our findings advance understanding of how complex reactions toward micro and macro aspects relate to relevant behaviors. This suggests that practically speaking, it might make sense for policymakers to focus less strongly on reducing the objective ambivalence on the level of concrete behaviors and instead seek to increase the objective ambivalence toward the overarching problem.

\section{Electronic Supplementary Materials}

The electronic supplementary material is available with the online version of the article at https://doi.org/ 10.1027/1864-9335/a000465

ESM 1. The file contains descriptions of additional items and exploratory analyses.

\section{References}

Adamson, M. M., Phillips, A., Seenivasan, S., Martinez, J., Grewal, H., Kang, X., Coetzee, J., Luttenbacher, I., Jester, A., Harris, O. A., \& Spiegel, D. (2020). International prevalence and correlates of psychological stress during the global COVID-19 pandemic. International Journal of Environmental Research and Public Health, 17(24), Article 9248. https://doi.org/10.3390/ ijerph17249248

Alvarez, R. M., \& Brehm, J. (1995). American ambivalence towards abortion policy: Development of a heteroskedastic probit model of competing values. American Journal of Political Science, 39(4), 1055-1082. https://doi.org/10.2307/2111669

Armitage, C. J., \& Conner, M. (2000). Attitudinal ambivalence: A test of three key hypotheses. Personality and Social Psychology Bulletin, 26(11), 1421-1432. https://doi.org/10.1177/ 0146167200263009

Bargh, J. A., Chaiken, S., Govender, R., \& Pratto, F. (1992). The generality of the automatic attitude activation effect. Journal of Personality and Social Psychology, 62, 893-912. https://doi. org/10.1037/0022-3514.62.6.893

Bassili, J. N. (1996). Meta-judgmental versus operative indexes of psychological attributes: The case of measures of attitude strength. Journal of Personality and Social Psychology, 71(4), 637-653. https://doi.org/10.1037/0022-3514.71.4.637 
Baumeister, R. F., Vohs, K. D., \& Funder, D. C. (2007). Psychology as the science of self-reports and finger movements: Whatever happened to actual behavior? Perspectives on Psychological Science, 2(4), 396-403. https://doi.org/10.1111/j.17456916.2007.00051.x

Berrios, R., Totterdell, P., \& Kellett, S. (2018). Silver linings in the face of temptations: How mixed emotions promote self-control efforts in response to goal conflict. Motivation and Emotion, 42(6), 909-919. https://doi.org/10.1007/s11031-018-9707-1

Bundesministerium für Gesundheit. (2021). Coronavirus-Pandemie (SARS-CoV-2): Chronik bisheriger Maßnahmen und Ereignisse [Coronavirus-Pandemic (SARS-CoV-2): Chronic of previous measures and events]. https://www.bundesgesundheitsministerium.de/coronavirus/chronik-coronavirus.html

Cacioppo, J. T., \& Berntson, G. G. (1994). Relationship between attitudes and evaluative space: A critical review, with emphasis on the separability of positive and negative substrates. Psychological Bulletin, 115(3), 401-423. https://doi.org/ 10.1037/0033-2909.115.3.401

Carvalho, T., Krammer, F., \& Iwasaki, A. (2021). The first 12 months of COVID-19: A timeline of immunological insights. Nature Reviews Immunology, 21(4), 245-256. https://doi.org/10.1038/ s41577-021-00522-1

Costarelli, S., \& Colloca, P. (2004). The effects of attitudinal ambivalence on pro-environmental behavioural intentions. Journal of Environmental Psychology, 24(3), 279-288. https:// doi.org/10.1016/j.jenvp.2004.06.001

Conner, M., \& Armitage, C. J. (2008). Attitudinal ambivalence. In W. Crano \& R. Prislin (Eds.), Attitudes and attitude change (pp. 261-286). Psychology Press.

Dohle, S., Wingen, T., \& Schreiber, M. (2020). Acceptance and adoption of protective measures during the COVID-19 pandemic: The role of trust in politics and trust in science. Social Psychological Bulletin, 15(4), Article e4315. https://doi.org/ $10.32872 / \mathrm{spb} .4315$

Fiedler, K. (2007). Construal level theory as an integrative framework for behavioral decision-making research and consumer psychology. Journal of Consumer Psychology, 17(2), 101106. https://doi.org/10.1016/S1057-7408(07)70015-3

Folkman, S., \& Moskowitz, J. T. (2000). Stress, positive emotion, and coping. Current Directions in Psychological Science, 9(4), 115-118. https://doi.org/10.1111/1467-8721.00073

Gamonal-Limcaoco, S., Montero-Mateos, E., Lozano-López, M. T., Maciá-Casas, A., Matías-Fernández, J., \& Roncero, C. (2021). Perceived stress in different countries at the beginning of the coronavirus pandemic. The International Journal of Psychiatry in Medicine. https://doi.org/10.1177/00912174211033710

Gebauer, J. E., Maio, G. R., \& Pakizeh, A. (2013). Feeling torn when everything seems right: Semantic incongruence causes felt ambivalence. Personality and Social Psychology Bulletin, 39(6), 777-791. https://doi.org/10.1177/0146167213481679

Gillebaart, M., Schneider, I. K., \& De Ridder, D. T. (2016). Effects of trait self-control on response conflict about healthy and unhealthy food. Journal of Personality, 84(6), 789-798. https://doi.org/10.1111/jopy.12219

Glöckner, A., Dorrough, A. R., Wingen, T., \& Dohle, S. (2020, July 22). The perception of infection risks during the early and later outbreak of COVID19 in Germany: consequences and recommendations. https://psyarxiv.com/wdbgc/

Hellmann, D. M., Dorrough, A. R., \& Glöckner, A. (2021). Prosocial behavior during the COVID-19 pandemic in Germany. The role of responsibility and vulnerability. Heliyon, 7(9), Article e08041. https://doi.org/10.1016/j.heliyon.2021.e08041

Hershfield, H. E., Scheibe, S., Sims, T. L., \& Carstensen, L. L. (2013). When feeling bad can be good: Mixed emotions benefit physical health across adulthood. Social Psychological and
Personality Science, 4(1), 54-61. https://doi.org/10.1177/ 1948550612444616

Hunter, P. R. (2021). Thrombosis after COVID-19 vaccination. British Medical Journal, 2021, Article 373. https://doi.org/ 10.1136/bmj.n958

Imhoff, R., \& Lamberty, P. (2021). A bioweapon or a hoax? The link between distinct conspiracy beliefs about the coronavirus disease (COVID-19) outbreak and pandemic behavior. Social Psychological and Personality Science, 11(8), 1110-1118. https://doi.org/10.1177/1948550620934692

Jamieson, D. W. (1993, August). The attitude ambivalence construct: Validity, utility, and measurement. Paper presented at the annual meeting of the American Psychological Association, Toronto.

Kaplan, K. J. (1972). On the ambivalence-indifference problem in attitude theory and measurement: A suggested modification of the semantic differential technique. Psychological Bulletin, 77(5), 361-372. https://doi.org/10.1037/h0032590

Larsen, J. T., Hemenover, S. H., Norris, C. J., \& Cacioppo, J.T. (2003). Turning adversity to advantage: On the virtues of the coactivation of positive and negative emotions. In L. G. Aspinwall \& U. M. Staudinger (Eds.), A psychology of human strengths: Fundamental questions and future directions for a positive psychology (pp. 211-225). American Psychological Association. https://doi.org/10.1037/10566-015

Lüscher, K., \& Pillemer, K. (1998). Intergenerational ambivalence: A new approach to the study of parent-child relations in later life. Journal of Marriage and the Family, 60(2), 413-425. https://doi.org/10.2307/353858

Maio, G. R., Fincham, F. D., \& Lycett, E. J. (2000). Attitudinal ambivalence toward parents and attachment style. Personality and Social Psychology Bulletin, 26(12), 1451-1464. https://doi. org/10.1177/01461672002612001

Marcus, G. E. (2010). Sentimental citizen: Emotion in democratic politics. Penn State Press.

Marcus, G. E., Neuman, W. R., \& MacKuen, M. (2000). Affective intelligence and political judgment. University of Chicago Press.

Newby-Clark, I. R., McGregor, I., \& Zanna, M. P. (2002). Thinking and caring about cognitive inconsistency: When and for whom does attitudinal ambivalence feel uncomfortable? Journal of Personality and Social Psychology, 82(2), 157-166. https://doi. org/10.1037/0022-3514.82.2.157

Nisbett, R. E., \& Miyamoto, Y. (2005). The influence of culture: Holistic versus analytic perception. Trends in Cognitive Sciences, 9(10), 467-473. https://doi.org/10.1016/j.tics.2005.08.004

Nohlen, H. U. (2015). Solving ambivalence in context: The experience and resolution of attitudinal ambivalence. https://pure. uva.nl/ws/files/2564891/164939_Nohlen_binnenwerk_FINAL_ complete.pdf

Nohlen, H. U., van Harreveld, F., \& Cunningham, W. A. (2019). Social evaluations under conflict: Negative judgments of conflicting information are easier than positive judgments. Social Cognitive and Affective Neuroscience, 14(7), 709-718. https://doi.org/10.1093/scan/nsz045

Ojala, M. (2005). Adolescents' worries about environmental risks: Subjective well-being, values, and existential dimensions. Journal of Youth Studies, 8(3), 331-347. https://doi.org/ $10.1080 / 13676260500261934$

Ojala, M. (2008). Recycling and ambivalence: Quantitative and qualitative analyses of household recycling among young adults. Environment and Behavior, 40(6), 777-797. https://doi. org/10.1177/0013916507308787

Peer, E., Brandimarte, L., Samat, S., \& Acquisti, A. (2017). Beyond the Turk: Alternative platforms for crowdsourcing behavioral research. Journal of Experimental Social Psychology, 70, 153163. https://doi.org/10.1016/j.jesp.2017.01.006 
Plambeck, N., \& Weber, K. (2009). CEO ambivalence and responses to strategic issues. Organization Science, 20(6), 993-1010. https://doi.org/10.1287/orsc.1090.0471

Povey, R., Wellens, B., \& Conner, M. (2001). Attitudes towards following meat, vegetarian and vegan diets: an examination of the role of ambivalence. Appetite, 37(1), 15-26. https://doi.org/ 10.1006/appe.2001.0406

Priester, J. R., \& Petty, R. E. (1996). The gradual threshold model of ambivalence: Relating the positive and negative bases of attitudes to subjective ambivalence. Journal of Personality and Social Psychology, 71(3), 431-449. https://doi.org/10.1037/ 0022-3514.71.3.431

Priester, J. R., \& Petty, R. E. (2001). Extending the bases of subjective attitudinal ambivalence: Interpersonal and intrapersonal antecedents of evaluative tension. Journal of Personality and Social Psychology, 80(1), 19-34. https://doi.org/10.1037/ 0022-3514.80.1.19

R Core Team. (2020). R: A language and environment for statistical computing. R Foundation for Statistical Computing. https:// www.R-project.org/

Rees, L., Rothman, N. B., Lehavy, R., \& Sanchez-Burks, J. (2013). The ambivalent mind can be a wise mind: Emotional ambivalence increases judgment accuracy. Journal of Experimental Social Psychology, 49(3), 360-367. https://doi.org/10.1016/ j.jesp.2012.12.017

Righetti, F., Schneider, I., Ferrier, D., Spiridonova, T., Xiang, R., \& Impett, E. A. (2020). The bittersweet taste of sacrifice: Consequences for ambivalence and mixed reactions. Journal of Experimental Psychology: General, 149(10), 1950-1968. https:// doi.org/10.1037/xge0000750

Rothman, N. B., \& Melwani, S. (2017). Feeling mixed, ambivalent, and in flux: The social functions of emotional complexity for leaders. Academy of Management Review, 42(2), 259-282. https://doi.org/10.5465/amr.2014.0355

Rothman, N. B., Pratt, M. G., Rees, L., \& Vogus, T. J. (2017). Understanding the dual nature of ambivalence: Why and when ambivalence leads to good and bad outcomes. Academy of Management Annals, 11(1), 33-72. https://doi.org/10.5465/ annals.2014.0066

Sagristano, M. D., Trope, Y., \& Liberman, N. (2002). Timedependent gambling: Odds now, money later. Journal of Experimental Psychology: General, 131(3), 364-376. https:// doi.org/10.1037/0096-3445.131.3.364

Schneider, I. K., Dorrough, A., \& Frank, C. (2021). Data, materials, and analysis scripts for "Ambivalence and self-reported adherence to recommendations to reduce the spread of COVID-19". https://osf.io/eu6k5/

Schneider, I. K., Gillebaart, M., \& Mattes, A. (2019). Meta-analytic evidence for ambivalence resolution as a key process in effortless self-control. Journal of Experimental Social Psychology, 85, Article 103846. https://doi.org/10.1016/j.jesp. 2019. 103846

Schneider, I. K., \& Mattes, A. (2021). Mix is different from nix: Mouse tracking differentiates ambivalence from neutrality. Journal of Experimental Social Psychology, 95, Article 104106. https://doi.org/10.1016/j.jesp.2021.104106

Schneider, I. K., \& Schwarz, N. (2017). Mixed feelings: The case of ambivalence. Current Opinion in Behavioral Sciences, 15, 39-45. https://doi.org/10.1016/j.cobeha.2017.05.012

Schneider, I. K., van Harreveld, F., Rotteveel, M., Topolinski, S., van der Pligt, J., Schwarz, N., \& Koole, S. L. (2015). The path of ambivalence: Tracing the pull of opposing evaluations using mouse trajectories. Frontiers in Psychology, 6, Article 996. https://doi.org/10.3389/fpsyg.2015.00996

Signorielli, N. (1991). Adolescents and ambivalence toward marriage: A cultivation analysis. Youth \& Society, 23(1), 121-149.
Simons, J. J. P., Schneider, I. K., \& Sanchez-Burks, J. (2018). Ambivalence, the person and the attitude object: Individual differences in the experience of ambivalence. PsyArXiv. https:// doi.org/10.31234/osf.io/f7tvd

Snyder, A. I., \& Tormala, Z. L. (2017). Valence asymmetries in attitude ambivalence. Journal of Personality and Social Psychology, 112(4), 555-576. https://doi.org/10.1037/pspa0000075

Sparks, P., Harris, P. R., \& Lockwood, N. (2004). Predictors and predictive effects of ambivalence. British Journal of Social Psychology, 43(3), 371-383. https://doi.org/10.1348/ 0144666042037980

Thielmann, I., Zimmermann, J., Leising, D., Hilbig, B. E., \& Back, M. (2017). Seeing is knowing: On the predictive accuracy of selfand informant reports for prosocial and moral behaviours. European Journal of Personality, 31(4), 404-418. https://doi. org/10.1002/per.2112

Thompson, M. M., Zanna, M. P., \& Griffin, D. W. (1995). Let's not be indifferent about (attitudinal) ambivalence. In R. E. Petty \& J. A. Krosnick (Eds.), Attitude strength: Antecedents and consequences (pp. 361-386). Erlbaum.

Trope, Y., \& Liberman, N. (2000). Temporal construal and timedependent changes in preference. Journal of Personality and Social Psychology, 79(6), 876-889. https://doi.org/10.1037/ 0022-3514.79.6.876

Van Harreveld, F., Nohlen, H. U., \& Schneider, I. K. (2015). Chapter Five - The ABC of ambivalence: Affective, behavioral, and cognitive consequences of attitudinal conflict. In J. M. Olson \& M. P. Zanna (Eds.), Advances in experimental social psychology (Vol. 52, pp. 285-324). Academic Press. https://doi.org/ 10.1016/bs.aesp.2015.01.002

Van Harreveld, F., van der Pligt, J., \& de Liver, Y. N. (2009). The agony of ambivalence and ways to resolve it: Introducing the MAID model. Personality and Social Psychology Review, 13(1), 45-61. https://doi.org/10.1177/1088868308324518

Van Harreveld, F., van der Pligt, J., de Vries, N. K., Wenneker, C., \& Verhue, D. (2004). Ambivalence and information integration in attitudinal judgment. British Journal of Social Psychology, 43(3), 431-447. https://doi.org/10.1348/0144666042037971

World Health Organization. (2021a). COVID-19 weekly epidemiological update, August 10th 2021. https://www.who.int/ publications $/ \mathrm{m} /$ item/weekly-epidemiological-update-oncovid-19-10-august-2021

World Health Organization. (2021b). Slow vaccine roll-out prolonging pandemic. https://www.euro.who.int/en/media-centre/ sections/ press-releases/2021/slow-vaccine-roll-out-prolongingpandemic

\section{History}

Received May 15, 2021

Revision received October 5, 2021

Accepted October 18, 2021

Published online January 10, 2022

\section{Acknowledgments}

We gratefully acknowledge Andreas Glöckner, Simone Dohle, and Jeff Larsen for their generous support in data collection/sharing. We thank Jacqueline Bachmann for her excellent support in preparing this manuscript for submission.

\section{Authorship}

Iris K. Schneider and Angela R. Dorrough designed and conceptualized all studies and collected the data. Iris K. Schneider, Angela R. Dorrough, and Celine Frank performed data analyses. Iris K. Schneider drafted the manuscript. Angela R. Dorrough and Celine Frank provided constructive comments and editing. Celine Frank is a master student working under supervision of the first author. 


\section{Open Data}

We preregistered all studies and conducted analyses in line with the preregistration using statistical analyses packages in R (2020) (Schneider et al., 2021). Data, materials (including all measures), and analysis scripts can be found on the Open Science Framework page (Schneider et al., 2021).

\section{Funding}

Open access publication enabled by University of Cologne.

\section{ORCID}

Iris K. Schneider

(iD) https://orcid.org/0000-0003-0915-0809

\section{Iris K. Schneider}

Department of Psychology

University of Cologne

Richard-Strauss-Str 2

50931 Cologne

Germany

i.k.schneider@uni-koeln.de 